http://ejournal.upi.edu/index.php/jaz/ - e-mail: jurnal.zonasi@gmail.com dan jurnal_zonasi@upi.edu DOI: http://10.17509/jaz.v1i2.13509

\title{
KEBERADAAN ACTIVITY SUPPORT YANG MEMPENGARUHI AKSESIBILITAS PADA PERMUKIMAN DI SEKITARNYA
}

\section{Studi Kasus: Koridor Jalan Kadipaten Raya Antapani Kota Bandung}

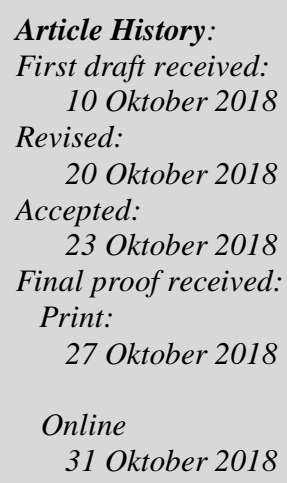

\author{
Gina Nur Zuraida H. ${ }^{1}$, Karto Wijaya ${ }^{2}$, Rahy R. Sukardi ${ }^{3}$ \\ 1,2,3, Program Studi Arsitektur Universitas Kebangsaan, Bandung, Indonesia \\ Jl. Terusan Halimun No. 37, Pelajar Pejuang 45, Bandung \\ Email: ginanurzh@gmail.com, \\ kartowijaya@universitaskebangsaan.ac.id, \\ rahy@universitaskebangsaan.ac.id,
}

\begin{abstract}
The needs of the board is one of the primary needs for human to be able to live, therefore created the settlement. As a space that embodies the life of human settlements develop not only as a collection of home buildings but also equipped with facilities and infrastructure supporting human activities in it. In addition to be able to meet the needs of human life, there are also building means of supporting facilities in residential areas. All of these activities often occur in the same area, because they need to be reviewed where the developments are in the applicable regulations.
\end{abstract}

Keywords: settlement, facilities and infrastructure, environmental road.

Abstrak: Kebutuhan papan adalah salah satu kebututuhan primer untuk manusia agar dapat bisa hidup, oleh karena itu terciptalah permukiman. Sebagai ruang yang mewadahi kehidupan manusia permukiman berkembang bukan hanya sebagai kumpulan bangunan rumah namun juga di lengkapi dengan sarana dan prasarana penunjang kegiatan manusia yang ada di dalamnya. Selain itu untuk dapat memenuhi kebutuhan-kebutuhan hidup manusia, juga terdapat bangunan sarana sarana penunjang di area permukiman. Seluruh kegiatan tersebut seringkali terjadi di satu area yang sama, oleh karena perlu di tinjau bangai mana perkembangan tersebut pada peraturan yang berlaku.

Kata Kunci: permukiman, sarana dan prasarana, jalan lingkungan.

\section{Pendahuluan}

\subsection{Latar Belakang Masalah}

Manusia sebagai mahluk sosial tidak dapat hidup sendiri, harus bermasyarakat. Sebagai makhluk sosial manusia melakukan interaksi dengan sesama manusia lainnya, dan proses interaksi tersebut dikenali sebagai proses komunikasi. Permukiman merupakan salah satu wujud dari arsitektur pada skala kawasan. Permukiman dapat kita lihat sebagai wujud arsitektur yang lebih kompleks, karena di dalamnya tercakup beberapa system fungsi dan kegiatan, seperti system sosial budaya, system ekonomi, maupun struktur lingkungan (Sabarudin, 2016).

Permukiman adalah kawasan yang didominasi oleh lingkungan yang dilengkapi dengan prasarana dan sarana lingkungan (Budihardjo, 1997) dan tempat kerja yang memberikan pelayanan dan kesempatan kerja yang terbatas untuk mendukung perikehidupan dan penghidupan, sehingga fungsinya dapat berdaya guna dan berhasil guna. Permukiman ini dapat berupa permukiman perkotaan maupun permukiman perdesaan (Soetomo, 2012; Permana, 2012; Permana, Soetomo, Hardiman, dan Buchori, 2013). Permukiman merupakan lingkungan tempat tinggal manusia (Budihardjo, 1997; Soetomo, 2012; Widjaja, 2013). Kawasan merupakan bagian dari lingkungan alam (Budihardjo, 1997). Kawasan permukiman adalah bagian dari lingkungan hidup yang baik berupa kawasan perkotaan dan perdesaan yang berfungsi sebagai lingkungan tempat tinggal dan 
hunian (Permana, Sumarna, \& Wijaya, 2017) untuk melakukan kegiatan yang mendukung kehidupannya (Sandana, 2014). Seiring dengan berjalannya waktu dan pertumbuhan pemukiman semakin padat penduduk (Soetomo, 2012), dibangunlah bangunan penunjang permukiman seperti bangunan pendidikan (Permana, 2014) dan bangunan penunjang ekonomi (Masykur, 2005) yang tujuan dibangunnya adalah untuk memfasilitasi penduduk yang ada di pernukiman sekitar (Bintarto, 1983). Perumahan memberikan kesan tentang rumah atau kumpulan rumah beserta prasarana dan sarana ligkungannya. Dengan demikian perumahan dan pemukiman merupakan dua hal yang tidak dapat dipisahkan dan sangat erat hubungannya, pada hakekatnya saling melengkapi (Wijaya, Permana, dan Swanto, 2017). Pertumbuhan yang terjadi di fasilitasfasilitas penunjang tersebut justru terus mengalami perkembangan yang cukup signifikan. Maka dari itu dalam kasus ini membahas bagaimana perkembangan bangunan penunjang yang pada akhirnya menjadi suatu perumahan yang berada di tengah lingkungan permukiman, dan dampaknya terhadap permukiman itu sendiri.

\subsection{Permasalahan}

Berbagai kegiatan yang terjadi dalam suatu kompleks kecil membuat fasilitas yang ada tidak dapat menampung banyaknya orang yang beraktivitas secara bersamaan. Terdapat beberapa permasalahan yang dapat di angkat, yaitu:

- Lahan parkir sempit, banyak kendaraan, khususnya mobil yang parkir di luar kompleks Muhammadiah, yaitu pada jalan Kadipaten Raya.

- Tidak ada perberhentian khusus bagi orang tua yang mengantar dan menjemput siswa. Oleh karena itu kegiatan tersebut di lakukan di jalan Kadipaten raya.

- Tidak disediakan lahan khusus bagi penjual jajanan yang konsumen nya merupakan siswa SDN Muhammadiyah 7 dan SMP Muhammadiyah 8. para penjual tersebut juga menggunakan badan jalan kadipaten raya untuk berjualan. Siswa akan berkeliaran di jalan tersebut saat waktu pulang sekolah

- Sering terjadi kemacetan di karenakan banyaknya kegiatan kompleks Muhammadiyah yang tumpah ke jalan Kadipaten raya. Hal tersebut memnggangu aktivitas warga pemukiman sekitar

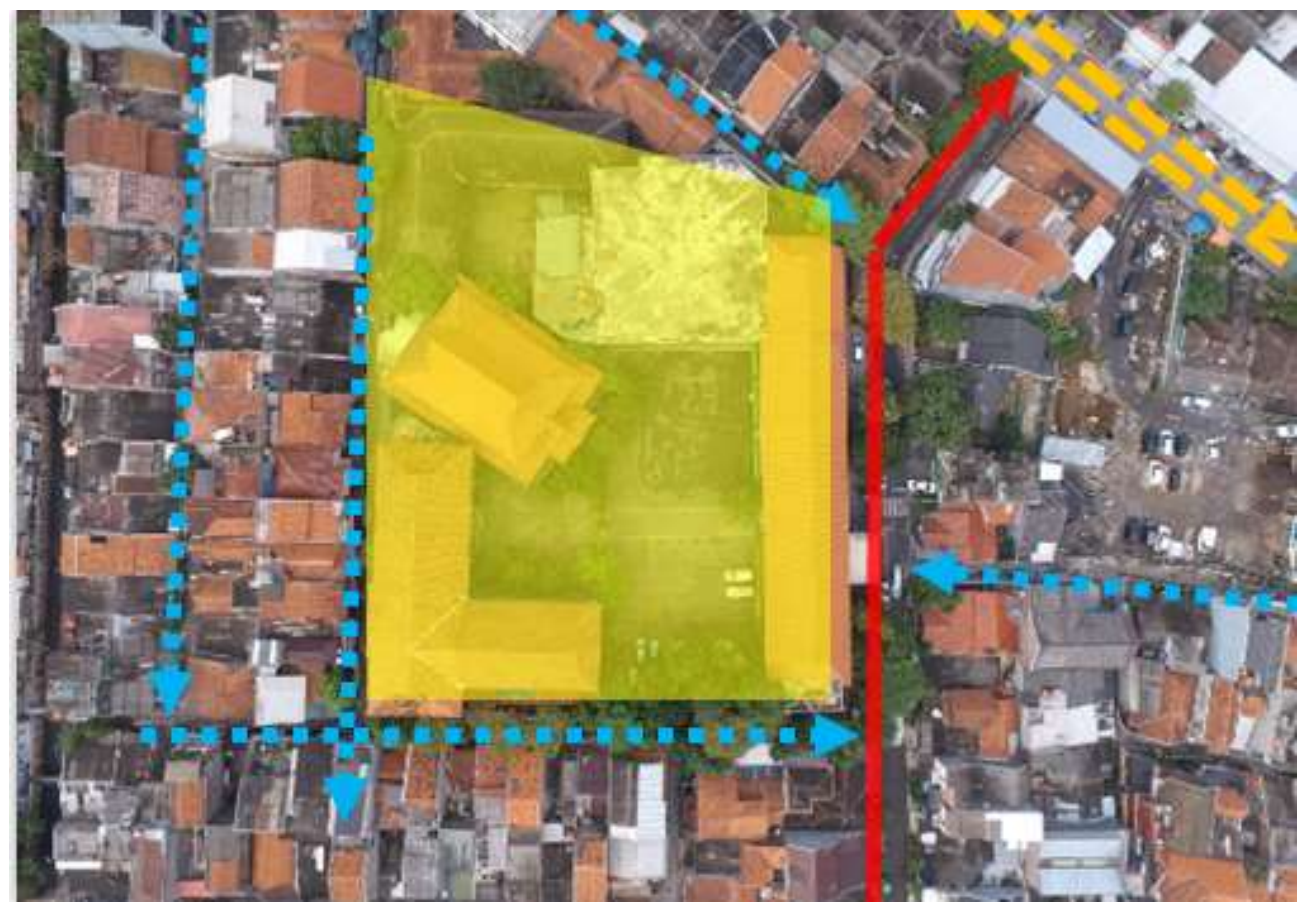

Gambar 2 Alur Transportasi Sekitar Kompleks Muhammadiyah Antapani Sumber: Google Maps

Keterangan

$n+\cdots$
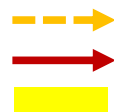

Jalan Pemukiman menuju Jalan Kadipaten Raya

Jalan Purwakarta, Jalan keluar menuju utama Antapani

Jalan Kadipaten Raya, dimana terletak gerbang Kompleks Muhammadiyah

Lokasi Kompleks Muhammadiyah 


\section{Metode Penelitian}

Metode penelitian yang digunakan dalam kajian ini adalah studi kasus. Studi literatur disini merupakan bagian dari proses mengumpulkan data dari proses observasi kondisi lapangan dimana penelitian di lakukan. Metode pendekatan analisis yang dipakai dalam studi kasus ini adalah pendekatan deskriptif. Deskriptif, yaitu metode analisis dengan cara melihat keadaan obyek penelitian melalui uraian, pengertian atau penjelasan terhadap analisis yang bersifat deskripsi keadan suatu lokasi amatan (Creswell, 1998). Penelitian deskriptif kualitatif bertujuan untuk mengungkap dan menggambarkan, meringkas berbagai kondisi, situasi, atau berbagai fenomena Pendekatan serealitas sosial yang ada di masyarakat yang menjadi objek penelitian, dan berupaya menarik realitas itu ke permukaan sebagai suatu ciri, karakter, sifat, model, tanda, atau gambaran tentang kondisi, situasi ataupun fenomena tertentu (Bungin, 2008).

Tujuan dari penelitian deskriftif kualitatif ini ditujukan untuk mendeskripsikan atau menggambarkan fenomena yang ada di lokasi amatan sehingga output yang di uraikan adalah deskripsi hasil amatan peneliti.

\section{Hasil dan Pembahasan}

Kompleks muhammadiyah Antapani ini pada awalanya hanya digunakan SD Muhammadiyah 7 dan TK Aisyiyah saja yang menjadi kegiatan utama di lahan ini. Namun seiring semakin baiknya kualitas dan predikat SD Muhammadiyah 7 semakin banyak juga peminat untuk menjadi siswa, yang mengharuskan pihak sekolah menambah bangunan dan fasilitas lainya. Selain itu dibangun juga SMP Muhammadiyah 8 dan Kantor Pimpinan daerah Muhammadiyah Kota Bandung. siswa yang bersekolah di sekolah ini mayoritas berasal dari keluarga menengah keatas, di tambah kantor muhammadiyah yang beroperasi di tempat yang sama membuat diperlukannya fasilitas yang sesuai dengan kebutuhan dari pengguna kompleks yang kebanyakan menggunakan kendaraan roda empat untuk beraktifitas.

\subsection{Lokasi}

Jalan Kadipaten Raya No.4-6, Antapani Kidul, Antapani, Antapani Kidul, Antapani, Kota Bandung, Jawa Barat

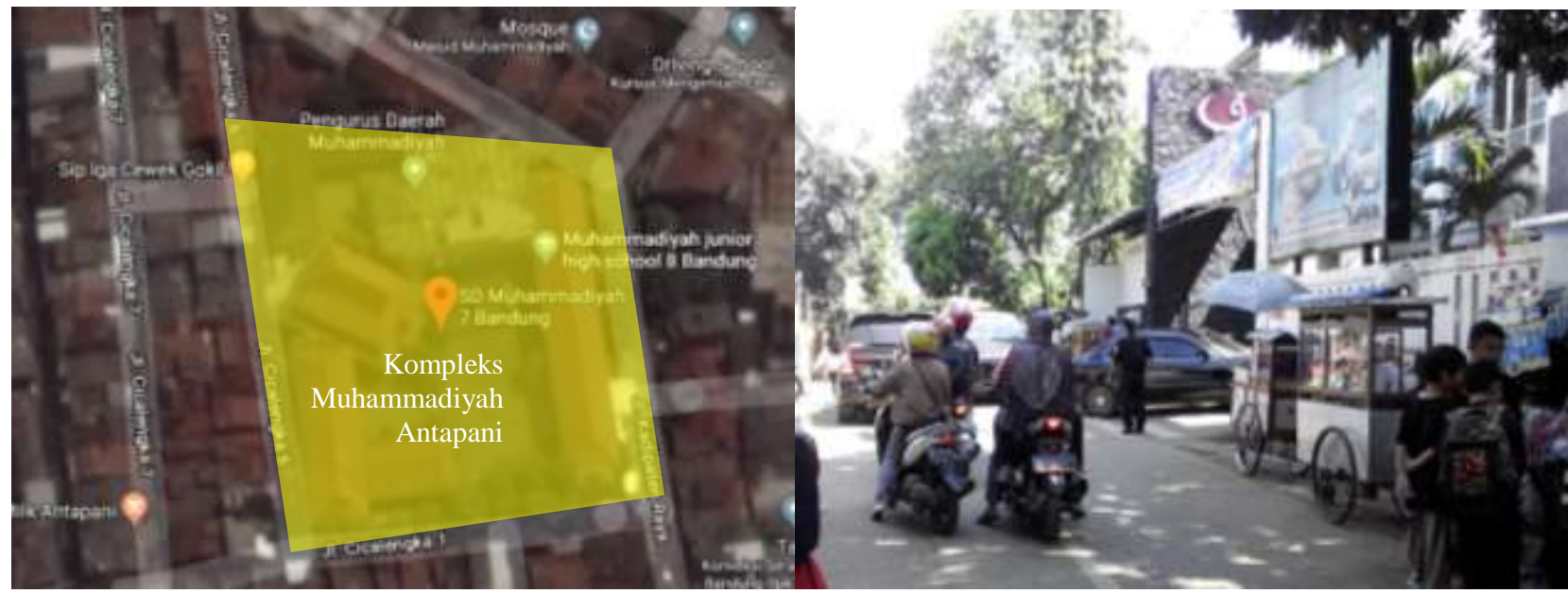

Gambar 1 Peta Kompleks Muhammadiyah Antapani Sumber: Google Maps

Terdapat empat kegiatan utama yang berlangsung, yaitu:

1. Pendidikan

- SD Muhammadiyah 7

- $\quad$ SMP Muhammadiyah 8

- TK Aisyiyah XII

2. Non Pendidikan

- Kantor Pimpinan daerah Muhammadiyah Kota Bandung 


\subsection{Potensi}

Potensi yang di timbulkan oleh kompleks ini cukup besar. Dengan berbasis keagamaan, kompleks ini sudah menjadi pusat pendidikan islami dan organisasi berbasis Muhammadiyah di Bandung Utara dan sampai saat ini masih terus berkembang. Dalam segi pendidikan sendiri sekolah-sekolah yang ada di kompleks ini memiliki predikat yang cukup baik dan terus meningkat tiap tahunnya, di tambah prestasi anak didiknya yang juga baik. Selain itu memiliki fasilitas yang cukup lengkap untuk menunjang kegiatan yang berlangsung.

Selain potensi internal dari kompleks tersebut, lokasinya yang berada di pemukiman padat, akan mudah menarik minat dari warga sekitar untuk bersekolah di sana, dalam segi ekonomi, kompleks tersebut banyak merekrut penduduk sekitar untuk menjadi pekerjanya, seperti menjadi staff guru, keamanan dan lain-lain. Selain itu banyak warga sekitar juga yang berjualan di kompleks tersebut. Kompleks ini juga termasuk berada lokasi yang strategis, dikelilingi perumahan, dekat dengan daerah komersil dan akses mudah di jangkau dari jalan utama Antapani.

\subsection{Analisis}

Peran Jalan Kadipaten Raya terhadap pemukiman sekitar merupakan jalan utama bagi warga sekitar untuk keluar masuk dari dan menuju pemukiman dari jalan raya. Terutama untuk warga yang menggunakan mobil dalam kegiatan sehari-harinya. Akibat yang di timbulkan selalu terjadi kemacetan di pagi hari yaitu sekitar jam 6.30 -7.00, dimana mayoritas warga berangkat kerja di waktu yang sama.

Pada jam tersebut juga terapkan system oneway di jalan kadipaten yang di usulkan oleh pihak muhammadiyah. Sedangkan menurut warga sekitar, mereka pun memiliki hak untuk menggunakan jalan tersebut tanpa harus ikut terkena kemacetan kendaraan yang mengantri untuk masuk, atau mengantar siswa muhammadiyah sebagai mana mestinya terutama pada pagi hari di mana mayoritas warga berangkat kerja.

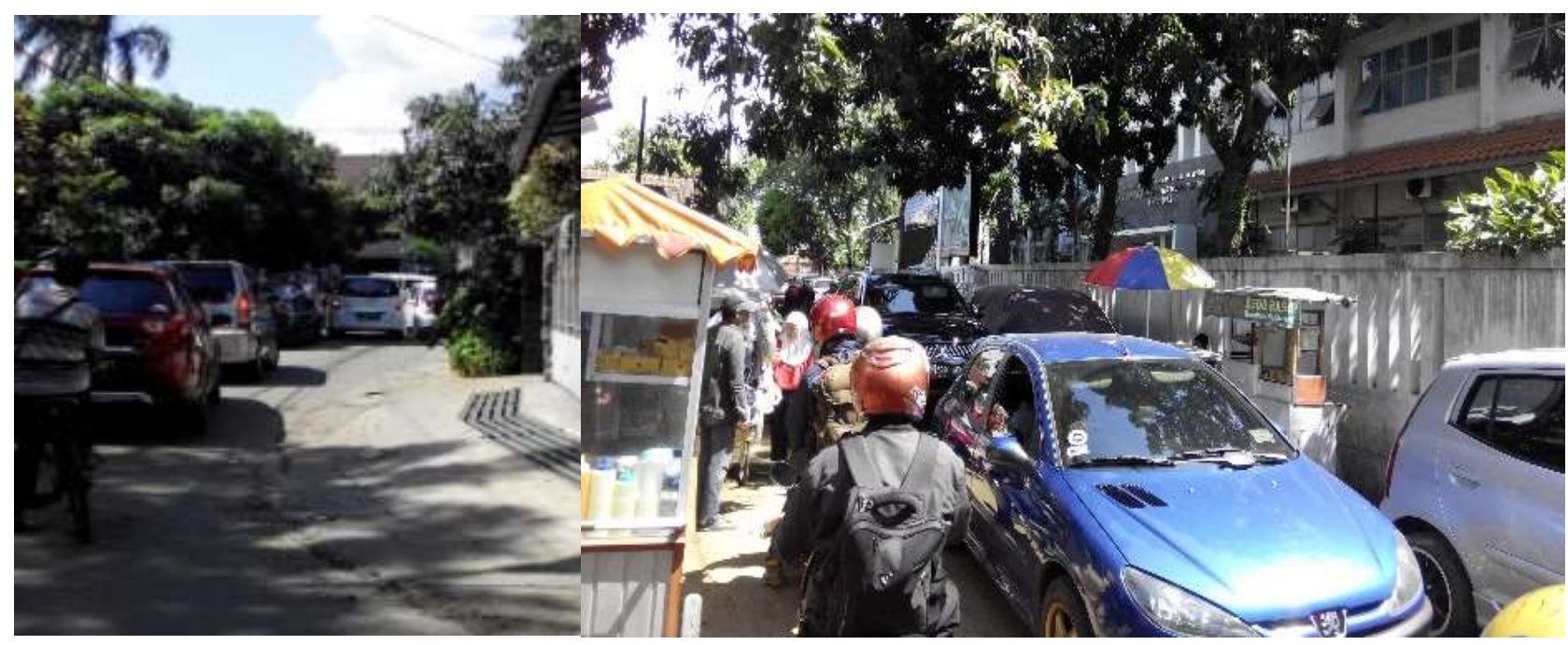

Gambar 3 Kemacetan Di Pagi Hari Kondisi saat ada kendaraan yang masuk ke kompleks Muhammadiyah Antapani Sumber: Dokumentasi Pribadi; Survei Lapangan 1 Maret 2018

Terjadi juga kemacetan pada sekitar jam 2.00 - 2.30 yaitu saat pulang sekolah. Disebabkan oleh kendaraan yang menjemput siswa muhammadiyah dan kegiatan siswa yang tumpah ke jalan. Warga sekitar harus ikut megantri saat orang tua murid menurunkan atau menaikan siswa ke dalam kendaraan. 


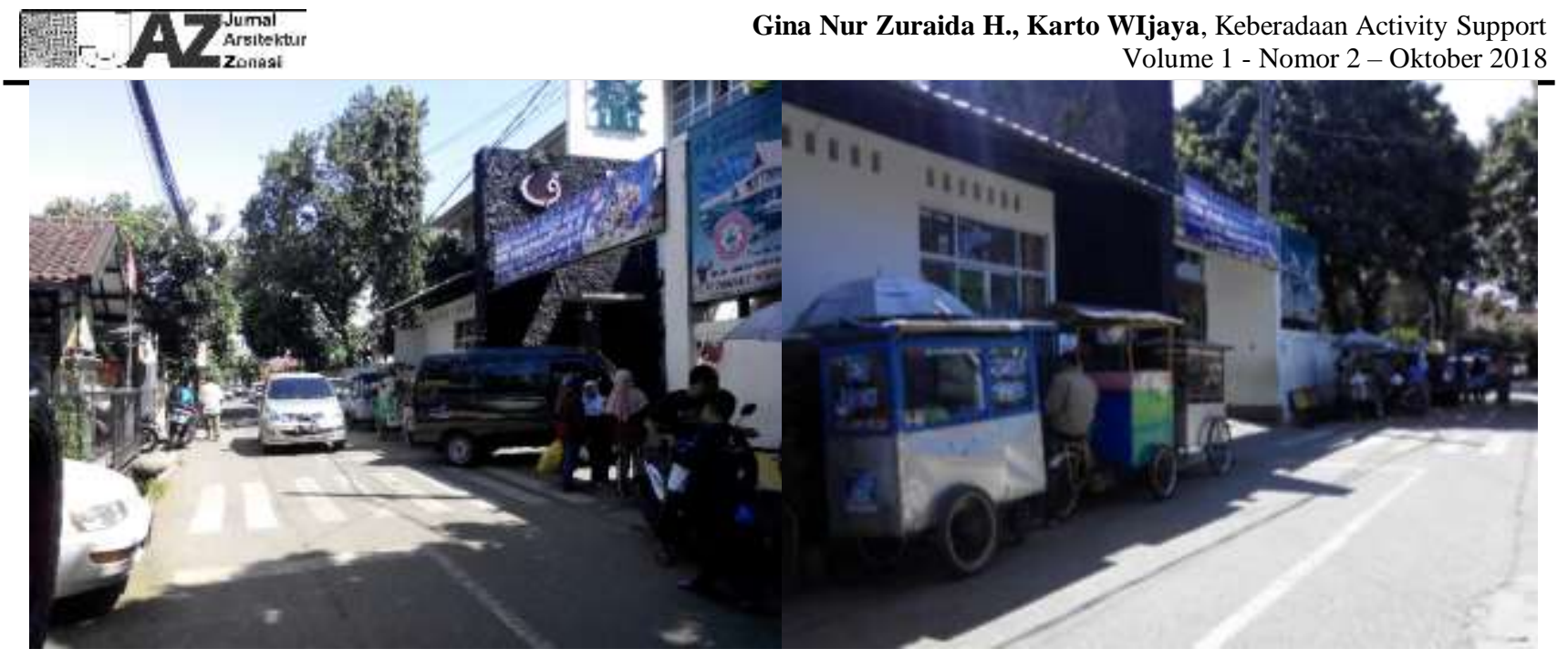

Gambar 4: Kondisi lebar jalan kadipaten di depan gerbang kompleks muhammadiyah antapani \& pedagang kaki lima yang berjualan di badan jalan kadipaten

Saat ada dua kendaraan/mobil yang bepapasan (di luar jam berlakunya oneway), tidak dapat maju bersamaan karena hampir sebagian badan jalan di pakai parkir mobil, atau di pakai berjualan. Karena tidak di sediakannya tempat untuk berjualan, seluruh pedagang kaki lima menggunakan badan jalan untuk berjualan. Oleh karena itu saat kegiatan jajan siswa muhammadiyah pada jam istirahat dan saata jam pulang sekolah akan mengganggu kelancaran transportasi di jalan tersebut.

Untuk menyelesaikan berbagai dampak yang terjadi, ada dua hal yang dapat di lakukan untuk menyelesaikan permasalahan tersebut.

- Membuat penyesuaian desain di dalam kompleks untuk menampung kegiatan-kegiatan yang menggunakan jalan di luar kompleks tersebut.

Melakukan rekayasa alur kendaraan, memperbolehkan mobil masuk kedalam kompleks tanpa parkir. Dan keluar melalui gerbang yang berbeda.

\section{Kesimpulan}

Perkembangan suatu fungsi lahan yang tidak terprediksi membuat absennya perencanaan yang matang dalam pengembangan lahan. Hal tersebut menciptakan suatu kompleks yang tidak dapat menampung segala kegiatan yang terjadi di dalamnya, imbasnya menjadikan fasilitas yang tadinya umum seakan menjadi fasilitas khusus yang di peruntukan kompleks tersebut. Membuat satu dampak negatif terhadap warga sekitar yang sama-sama memiliki hak untuk akses yang nyaman kapanpun sesuai dengan keberadaannya fasilitas tersebut sejak awal.

\section{Ucapan Terima Kasih}

Terima kasih kami ucapkan kepada prodi arsitektur FT Universitas Kebangsaan yang telah memberikan kesempatan untuk melakukan kolaborasi penelitian antara mehasiswa dengan dosen pada mata kuliah kota dan permukiman. Hasil dari penelitian ini kami berikan untuk menambah wawasan dan pengkayaan pada mata kuliah kota dan permukiman di lingkungan Kampus Universitas Kebangsaan khususnya dan kajian bidang arsitektur perkotaan serta pembaca pada umumnya .

\section{Referensi}

Bintarto. (1983). Interaksi Desa-Kota dan Permasalahannya (1st ed.). Jakarta: Ghalia Indonesia.

Budihardjo, E. (1997). Tata Ruang Perkotaan. Bandung: Alumni.

Bungin, M. B. (2008). PENELITIAN KUALITATIF: Komunikasi, Ekonomi, Kebijakan Publikdan Ilmu Sosial lainnya. Jakarta: Kencana Prenada Media Group.

Creswell, J. W. (1998). Qualitative Inquiry and Research Design. London: Sage Publications.

Masykur. (2005). Karakteristik Permukiman Dualistik dan Tingkat Keberhasilan Penghunian, studi kasus Kota Bogor Jawa Barat. Institut Pertanian Bogor.

Permana, A. Y. (2012). Peran Ruang Terbuka Publik dI Kawasan Slums DAN Squatters sebagai "Ruang Ketiga" (Kasus: Kawasan Bantaran Sungai Cikapundung di Kota Bandung. In SEMINAR NASIONAL 
"Sustainable Urbanism" Adaptasi Perubahan Ruang Perkotaan-Pendekatan Teoritik dan Praktek (pp. 84-98). Semarang: Media Plano : Biro Penerbit Planologi UNDIP.

Permana, A. Y. (2014). Transformasi Gubahan Ruang: Pondokan Mahasiswa di Kawasan Balubur Tamansari Kota Bandung. Universitas Diponegoro.

Permana, A. Y., Soetomo, S., Hardiman, G., \& Buchori, I. (2013). Smart Architecture as a Concept of Sustainable Development in the Improvement of the Slum Settlementarea in Bandung. Internasional Refereed Journal of Engineering and Science, 2(9), 26-35.

Permana, A. Y., Sumarna, N., \& Wijaya, K. (2017). Membangun Kampung Kreatif melalui Kolaborasi Mahasiswa dengan Masyarakat: Kasus Kawasan Balubur-Tamansari Kota Bandung (pp. 51-58). Padang: Program Pascasarjana Universitas Andalas.

Sabarudin, A. (2016). Permukiman Berkelanjutan. (L. Simarmata, Ed.). Jakarta: Erlangga.

Sandana, A. S. (2014). Perencanaan Kawasan Permukiman (1st ed.). Yogyakarta: Graha Ilmu.

Soetomo, S. (2012). Urbanisasi dan Morfologi. Proses perkembangan peradaban dan wadah ruang fisiknya: Menuju Ruang Kehidupan yang Manusiawi (2nd ed.). Yogyakarta: Graha Ilmu.

Widjaja, P. (2013). Kampung - Kota Bandung (Pertama). Yogyakarta: Graha Ilmu.

Wijaya, K., Permana, Y. A., \& Swanto, N. (2017). Kawasan Bantaran Sungai Cikapundung Sebagai Pemukiman Masyarakat Berpenghasilan Rendah (MBR) Di Kota Bandung. ARCADE, 1(2), 57-68. 